\title{
Identifying Features of Engineering Academic Units that Influence Teaching and Learning Improvement
}

\section{Dr. Kathleen Quardokus Fisher, Oregon State University}

Dr. Kathleen Quardokus Fisher is a postdoctoral scholar at Oregon State University. She is currently participating in a project that supports the use of evidence-based instructional practices in undergraduate STEM courses through developing communities of practice. Her research interests focus on understanding how organizational change occurs in higher education with respect to teaching and learning in STEM courses.

\section{Christina Smith, Oregon State University}

Christina Smith is a graduate student in the School of Chemical, Biological, and Environmental Engineering at Oregon State University. She received her B.S. from the University of Utah in chemical engineering and is pursuing her Ph.D. also in chemical engineering with an emphasis on engineering education. Her research focuses on how the beliefs of graduate students around teaching and learning interact with and influence the environments in which they are asked to teach.

\section{Ann Sitomer, Oregon State University}

Ann earned a $\mathrm{PhD}$ in mathematics education from Portland State University in 2014. Her dissertation examined the informal ways of reasoning about ratio, rate and proportion that adult returning students bring to an arithmetic review class and how these ways of thinking interacted with the curriculum. Other research interests include teachers' professional noticing of learners' mathematical thinking and organizational change. Ann works on both the implementation and research sides of the ESTEME@OSU project.

\section{Mr. John Ivanovitch, Oregon State University}

I am a third year doctoral student studying organizational change and science education at the collegiate level. My education includes a BA in cell and molecular Biology and a MSc. in integrated biochemistry/microbiology. Prior to entering the Doctoral program at Oregon State University I worked for over a decade as a biomedical researcher, with projects ranging from biochemistry to molecular virology. My current education research interests include transdisciplinary integration of STEM, and teaching-related cultures at the micro-, meso- and macro levels (i.e., discipline, departmental, institutional).

\section{Dr. Jana Bouwma-Gearhart, Oregon State University}

Jana L. Bouwma-Gearhart is an associate professor of STEM education at Oregon State University. Her research widely concerns improving education at research universities. Her earlier research explored enhancements to faculty motivation to improve undergraduate education. Her more recent research concerns organizational change towards postsecondary STEM education improvement at research universities, including the interactions of levers (people, organizations, policy, initiatives) of change and documenting the good, hard work required across disciplinary boundaries to achieve meaningful change in STEM education.

\section{Prof. Milo Koretsky, Oregon State University}

Milo Koretsky is a Professor of Chemical Engineering at Oregon State University. He received his B.S. and M.S. degrees from UC San Diego and his Ph.D. from UC Berkeley, all in Chemical Engineering. $\mathrm{He}$ currently has research activity in areas related engineering education and is interested in integrating technology into effective educational practices and in promoting the use of higher-level cognitive skills in engineering problem solving. His research interests particularly focus on what prevents students from being able to integrate and extend the knowledge developed in specific courses in the core curriculum to the more complex, authentic problems and projects they face as professionals. Dr. Koretsky is one of the founding members of the Center for Lifelong STEM Education Research at OSU. 


\title{
Identifying Features of Engineering Academic Units that Influence Teaching and Learning Improvement
}

\begin{abstract}
In this research paper, we use case study analysis to identify the features of three academic engineering departments at a research-doctoral university that influence the improvement of teaching and learning. Calls for improvement in engineering education, and broader STEM education, have identified the teaching practices of many faculty members as a weakness in higher education that leads to poor student achievement. Despite the evidence of the effectiveness of certain teaching practices (e.g., active learning), many faculty members rely heavily on didactic lecturing and rote memorization assessment. Faculty choice of teaching practices is influenced by individual characteristics, such as personal commitment to improving teaching, as well as the institutional characteristics of academic departments. Academic departments influence teaching choices because they provide (or withhold) external incentives and support for change in teaching practices, including resources, rewards, social acceptance, and job descriptions. Thus, change initiatives should assess these features prior to commencing. This assessment should lead to the development of change strategies to support individual and institutional characteristics that promote the use of evidence-based instructional practices.
\end{abstract}

Prior to the start of a university-wide change initiative, we focus on identifying the features of three engineering academic departments that are likely to influence improvement in teaching practices. This research was guided by two questions: (a) Within a doctoral-research institution, what are the characteristics of three engineering academic departments and of individuals within an academic department that influence the improvement of teaching and learning? (b) Using a conceptual framework that attends to the contextual and individual factors, what strategies do these identified features suggest a change agent should privilege when designing change initiative activities for these departments?

This study is part of a larger case study of the engineering departments. The data sources included in the case study are a survey of department members, interviews with administrators and educators, and classroom observations. This study focuses on the analysis of the survey of department members. In this survey, respondents were asked to identify expectations and practices at different levels of perspective (individual, classroom, and department), which influence teaching and learning improvement. This study describes these expectations and practices, and identifies change strategies according to these findings. Results indicate that both potentially positive and negative features for promoting change are present in the departments. For example, at the individual level, while educators report being dedicated to improving their practice, few educators report regularly enacting research-confirmed practices in their classroom. In this context, an appropriate change strategy might inform instructors about what type of activities could fulfill their commitment to improving their teaching, rather than trying to demonstrate the need for constant improvement. These results highlight the need to connect change strategies to the context of a department, classroom, and individual.

\section{Introduction}

The purpose of this paper is to explore the current state of three engineering departments regarding teaching and learning in order to develop change strategies to promote improvement in 
teaching practices. This investigation has begun at the beginning of an institution-based change initiative developed to promote evidence-based instructional practices in large enrollment undergraduate STEM courses. ${ }^{1}$ Three engineering departments, along with four other STEM disciplines, are involved in the change initiative. In order to develop change strategies, the context of the departments were explored through three levels of perspectives, individual, activity setting, and institutional. ${ }^{2}$ The activity setting that was chosen was the classroom or laboratory, and the institutional level is the department. These three levels influence the teaching practices enacted by individuals. For example, if the department culture values engagement in activities meant to improve teaching, then individuals within that culture are likely to engage in this practice. Likewise, if an individual is committed to engaging in evidence-based instructional practices in the classroom, then this dedication impacts practices. Thus, these three levels are explored to understand the context within which an individual lives. In addition, if one of these levels does not support improvement in teaching practices, then change strategies can be designed to address this need.

This institution-based change initiative was developed as a response to national calls for improvement. National organizations, including the Department of Education, are concerned with improving undergraduate STEM programs in order to graduate more students and to prepare graduates for contributing to the advancement of society and the political process. ${ }^{3,4,5}$ One of the features of undergraduate STEM programs that is continually identified by these groups as in need of improvement is the teaching practices of post-secondary educators. Researchers have identified a variety of strategies that can be enacted to promote teaching improvement, including co-teaching assignments, professional development, and policy adjustments. ${ }^{6,7,8}$ In addition, researchers also argue that the specific strategies employed by change agents must be appropriate for the context of the change initiative. ${ }^{6}$ In this study, we use three of Hedegaard's levels of perspectives from which a person's life can be viewed (individual, activity setting, and institutional) as the context of the change initiative. ${ }^{2}$ We identify the expectations as well as the current practices at these levels to discover features that can inform the design of strategies meant to promote change.

Using the conceptual framework of cultural historical activity theory, Hedegaard identified four levels of perspective from which a person's life may be viewed. These are the individual level, the activity setting level, the institutional level, and the societal level. ${ }^{2}$ The demands, expectations, and interactions of these levels impact the motives and behaviors of individuals, and in turn also the motives and behaviors of the other levels. In this study, we are interested in an individual's behavior within the classroom. Thus, we have identified the department as the institutional level, and the classroom as the activity setting. At the department level, the department members set expectations and boundaries on what type of behavior is acceptable to participate in that environment. For example, if very few department members discuss teachingrelated issues with their colleagues, then an individual is unlikely to adopt this practice of communication regardless of personal beliefs. The activity setting of the classroom provides more specified expectations for behavior. For example, the classroom setting has specific expectations for behavior from the students and the educator that may or may not apply to the institution at-large. Finally, the individual may have individual motives and expectations that reinforce the other levels of perspective or are in conflict with them. The fourth level, societal, is not addressed in this study. 
By investigating these three levels, this study describes the influences on teaching and learning within the engineering departments. We then suggest how the alignment or misalignment of the expectations and practices at these levels can inform the change strategies enacted within the department. For example, at the departmental level there may be an expectation that department members engage in teaching improvement activities, but this expectation might not be met in practice. Change strategies to address this misalignment should focus on support and structures to enable engagement rather than increasing the expectation for engagement. This analysis and discussion is guided by two research questions: (a) Within a doctoral-research institution, what are the characteristics of three engineering academic departments and of individuals within an academic department that influence the improvement of teaching and learning? (b) Using a conceptual framework that attends to the contextual and individual factors, what strategies do these identified features suggest a change agent should privilege when designing change initiative activities for these departments?

\section{Context}

This study is a preliminary analysis of the teaching and learning expectations and practices within three engineering units involved in an institution-based change initiative. The change initiative leadership has set out to accomplish several goals within and across the seven STEM units. The first goal of the change initiative is to promote evidence-based instructional practices in large-enrollment STEM undergraduate courses. The specific practices promoted by the change initiative leadership are interactive engagement with frequent formative feedback in lecture settings, and Cooperative Learning in laboratory settings. ${ }^{1,10}$ Second, the change initiative leadership promotes these practices through the development of Communities of Practice to support teaching within and across units, and the enhancement of existing Communities of Practice. ${ }^{111}$ These communities are intended to cross-pollinate ideas about the process of enacting evidence-based instructional practices and to support educators within the university who are engaged in evidence-based practice. Finally, the change initiative hopes to develop sustainable activities that will continue beyond the end of the change initiative's funding. ${ }^{1}$ In order to inform the specific strategies of change that can lead to these goals, this study is a preliminary investigation of the current state of the engineering departments.

\section{Methodology and Methods}

In this study, we present a portion of a larger case study of the departments involved in the change initiative. A case study relies on multiple sources of data to converge upon a single set of findings. ${ }^{12}$ The larger case study involves interviews, a survey, and classroom observations. In this study, we use an exploratory approach to investigate the findings of the survey and make preliminary claims regarding the context of the individual, classroom, and department level expectations and practices. These findings will be used to converge upon the findings of the larger case study. Although the survey contains quantitative data, we make qualitative observations to support the exploratory nature of the investigation of alignment and misalignment of expectations and practices. Instead of relying on quantitative methods for validity and reliability, the other data sources in the case study will be used to triangulate and validate these preliminary findings. 


\section{Results and Discussion}

The survey was sent to department members (tenure-track and non-tenure track) in the engineering departments. Table 1 is the response rates for the three departments. The survey questions that ask specifically about classroom expectations and practices were only asked of department members who regularly teach large-enrollment, lower-level undergraduate STEM courses. Thus, these questions have fewer respondents, which is noted, throughout this section.

Table 1. Response rates for the three engineering departments

\begin{tabular}{llll}
\hline Department & $\begin{array}{l}\text { Potential } \\
\text { Respondents }\end{array}$ & Respondents & Rate \\
\hline A & 26 & 20 & $77 \%$ \\
B & 40 & 17 & $43 \%$ \\
C & 47 & 27 & $57 \%$ \\
Total & 113 & 64 & $57 \%$ \\
\hline
\end{tabular}

The results subsections are organized by level of perspective. First the separate levels (department, classroom, and individual) results are reported and discussed. These separate levels are then connected to change initiative strategies. In the last section, we summarize the strategies that address the needs of the levels. For ease of reporting, the combined departmental responses are shown. In general, the separate department responses were consistent with the aggregate responses, but differences among the separate departments will be identified when they are present (Department A, B, and C).

\section{The Department Level}

The expectations and practices regarding (1) communication about teaching and learning and regarding (2) teaching development opportunities were explored at the department level. Many of these items were adopted from Knorek's departmental climate survey. ${ }^{13}$ Figure 1 are the results regarding communication about teaching and learning in the department. Communication about teaching and learning provides insight into the expectations of the department for sharing and co-constructing solutions to the challenges of instruction. Figure 2 reports the results regarding teaching development opportunities. The expectation for and availability of teaching development opportunities help the change initiative leadership determine if the department needs to be encouraged to become involved in opportunities and if opportunities are available to department members.

The communication questions in Figure 1 had two different response scales. The first five questions asked respondents to what extent they agreed with statements regarding communication about teaching and learning in the department. The gray bar indicates the transition from "agree" to "disagree." The last question in Figure 1 asked respondents to indicate the amount of time that they spent per week discussing teaching and learning with colleagues. The response scale to this question is a range of times, from none to 10 or more hours a week. The gray bar indicates the transition from "none" to "some but less than 3 hours."

In order to understand the expectations for communication at the level of department, respondents were asked if department administrators encouraged discussion with colleagues 
about teaching and learning. Across all three departments, approximately $60 \%$ of the respondents agreed at least slightly that their administrators encouraged communications about teaching with colleagues. In addition, Department B had even higher percentage of respondents who agreed with this statement. Administrators in all of the departments support the expectation for communication between colleagues. Accordingly, it will not be necessary for the change initiative leadership to develop strategies to convince administrators to encourage communication.

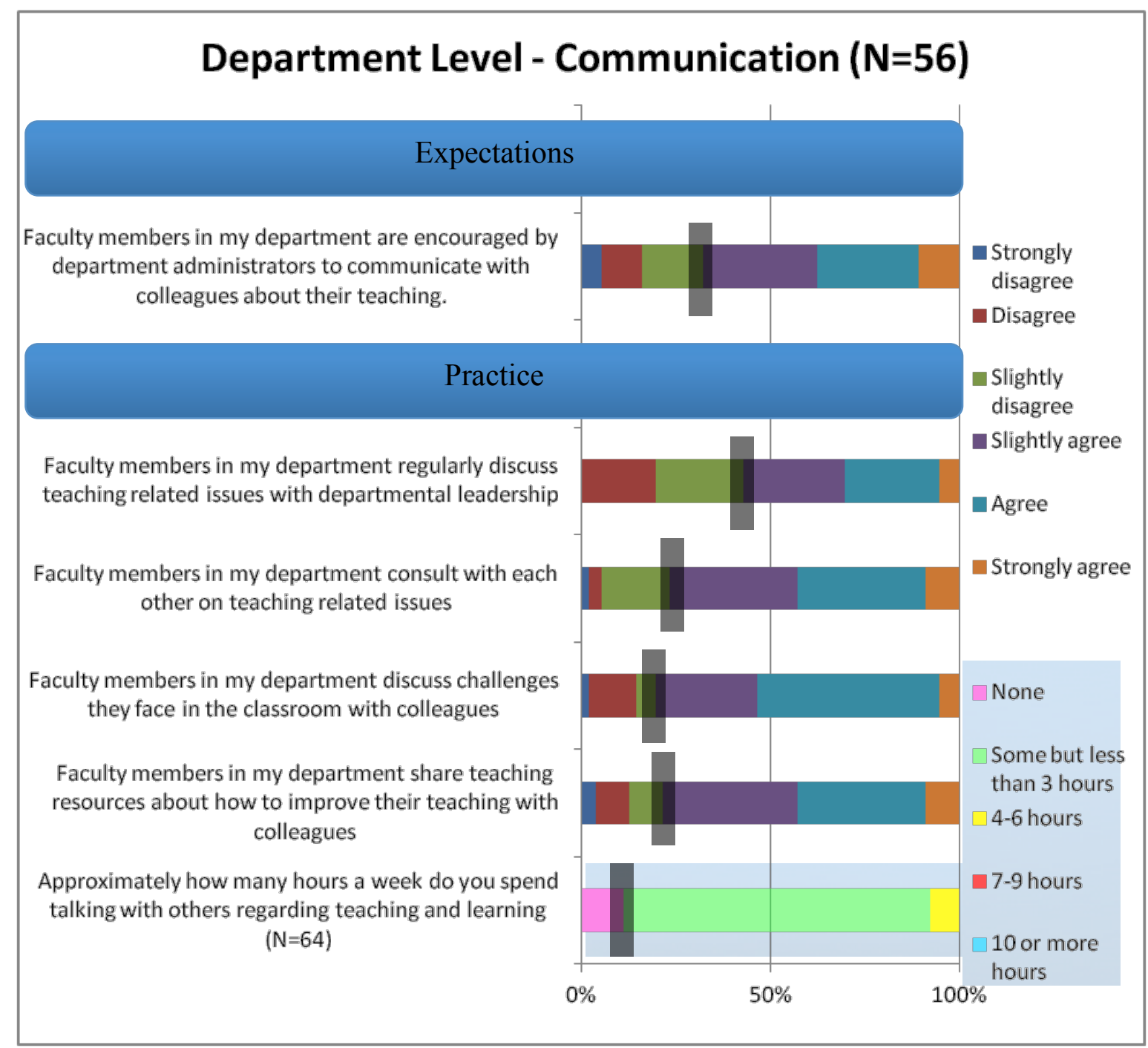

Figure 1. The expectations and practices at the departmental level regarding communication about teaching and learning

The administrators of the departments have set an expectation for colleagues to communicate about teaching, but the department members' practices may not include communication about teaching and learning. The remaining questions in Figure 1 investigate if communication between colleagues is practiced in the department. In general, the spectrum of agreement with statements about communication is the same in practice as it was in expectations. The amount of agreement by respondents with the statement "Faculty members in my department regularly 
discuss teaching related issues with departmental leadership" has the most negative response. This may be surprising given that communication is an expectation that is supported by administrators. This may indicate that communication is expected between faculty and not between administrators and faculty.

The positive expectations for communication and the practice of communication with faculty are an encouraging sign for the leadership of the change initiative. The change initiative strategies can target these communications to promote evidence-based instructional practices and to share practical advice about how to use these practices. These communications between colleagues are relatively short in duration from week to week (less than three hours). This means the information that passes between colleagues on a weekly basis cannot be overly complex. The more complicated aspects of instructional practices may need to be shared during more formal, extensive interactions, such as workshops. In addition, the change initiative leadership needs to develop strategies for communicating and promoting teaching practices to the administrative leadership because this type of communication is not practiced in the departments.

The second aspect of the department level explored was expectations and practices regarding teaching development opportunities. Figure 2 shows the responses to these questions. For expectations, respondents were asked to what degree they agreed that faculty members in the department believed that teaching improvement is part of their job and if they valued teaching development opportunities. To assess the practices in the department, respondents agreed or disagreed with statements about the availability of teaching development opportunities within their department and for new faculty members.

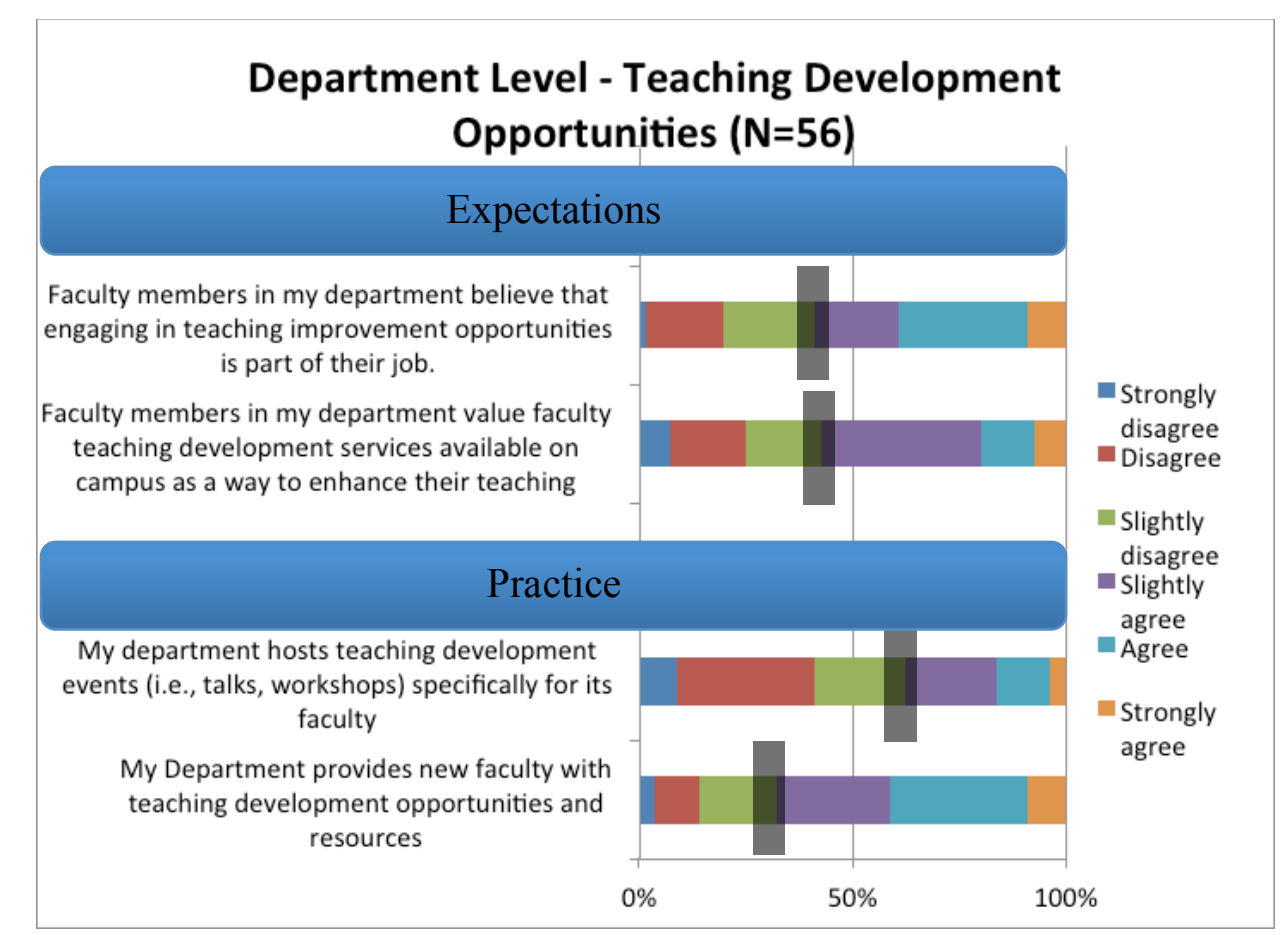

Figure 2. Expectations and practices at the departmental level regarding teaching development opportunities. 
The aggregate responses for the statements regarding expectations for valuing and engaging in teaching development opportunities were nearly split between agreeing and disagreeing. A slight tendency exists towards agreeing that engagement in these opportunities is expected and that the opportunities are valued. In Department $C$, the tendency towards negative expectations was higher for both engagement and valuing. Given this even split in expectations, it may be likely that the practice of hosting teaching development opportunities would also be evenly split. In fact, only $35 \%$ of respondents agree that their department hosts teaching development events. The amount of respondents that agree with the statement rises to $60 \%$ when the opportunities are focused for new faculty members.

The even split of expectations for engaging in and valuing teaching development opportunities should be of concern to the leadership of the change initiative. Change strategies should target the climate of the department to encourage participation. In addition, the departments do not host teaching development opportunities. The adopted change strategies will need to also include developing teaching improvement opportunities. This is particularly concerning, given that the earlier results of communication that suggested that avenues were needed to have longer, complex communications about teaching. These strategies also will need to address the activity setting of the classroom and the individual expectations and practices explore in the following sections.

\section{Classroom Level}

The classroom level represents the perspective of the activity setting for teaching and learning. This level has expectations and practices that may be unique from the department or the individual. In a classroom, the instructor, students, and teaching assistants often have specific roles that are expected of them. To explore these expectations, the respondents were asked what classroom practices they valued and how frequently they enacted these same practices (or facilitated the enactment of these practices through teaching assistants). The teaching practices investigated were: having students work with one another, holding whole-class discussions, having students give presentations, having students work individually on problems or tasks, lecturing, and asking students to explain their thinking. These questions were based upon similar questions asked by a study of the characteristics of successful calculus programs (CSPCC) that were available online. ${ }^{14}$ Only department members who typically taught large-enrollment, lowerdivision undergraduate courses answered these questions. The differences in the departments are not discussed in this section because of the small number of responses from each department.

Figure 3 displays the responses to the expectations and practices of respondents at the classroom level. The items that addressed the expectations of classroom practices asked respondents to indicate if each practice is important or unimportant. The two most important practices were having students work with one another and having students work individually on problems or tasks. In contrast, the most unimportant practices were having students give presentations, holding whole-class discussions, and lecturing. If these expectations are realized in the classroom then the response to the practices items should mirror these results. 


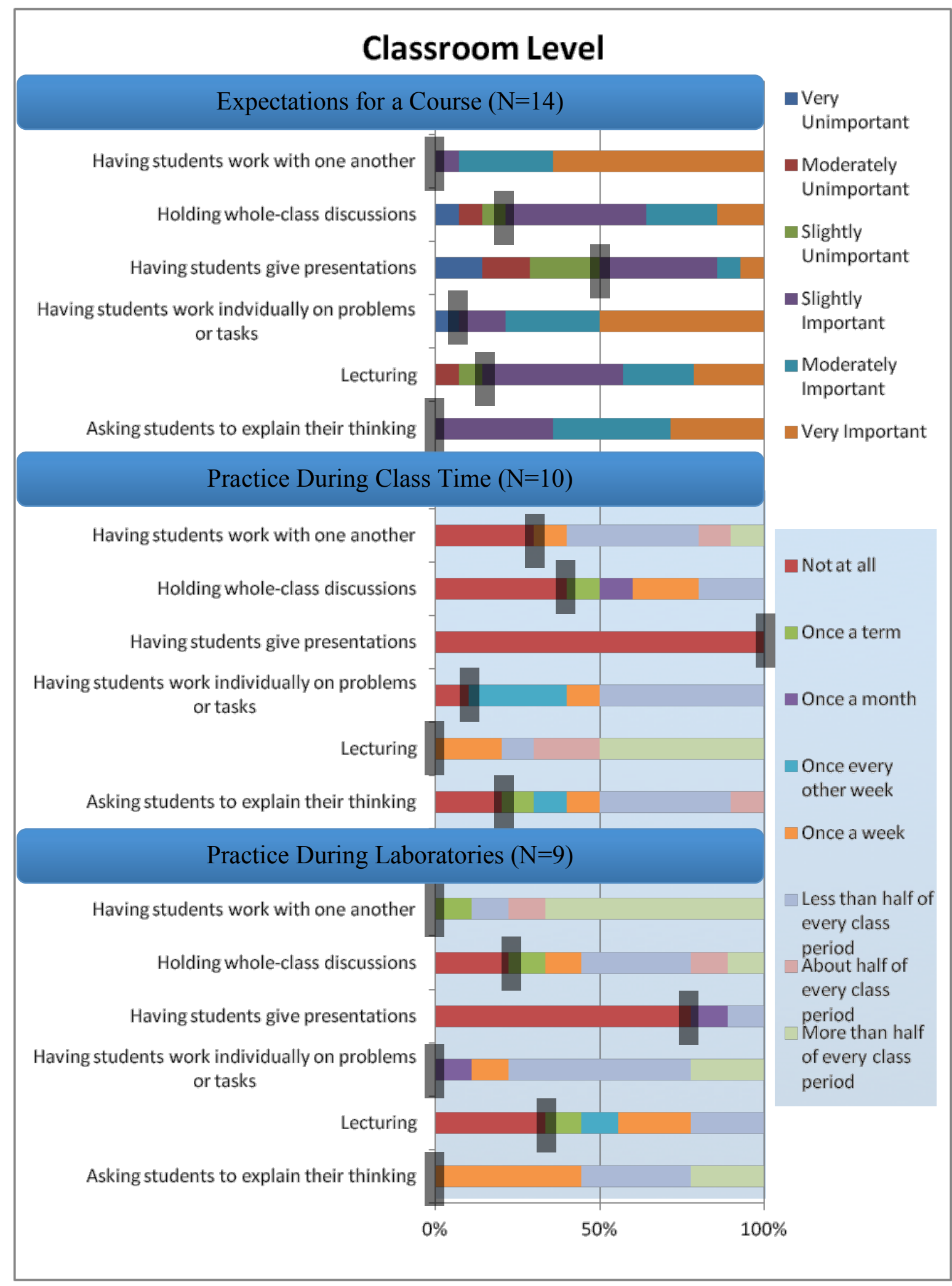

Figure 3. The expectations and practices at the classroom level regarding teaching and learning. Black bars on each item indicate the point of transition from "unimportant" to "important" or "not at all" to at least "once a term." 
The practices portion of the classroom level was split between practices in class time and practices in laboratory meetings. For class time, the most frequently occurring practices were lecturing, having students work with one another, and asking students to explain their thinking. The least frequent practices include having students give presentations and holding whole-class discussion. During laboratories, the most frequent practices were having students work with one another, having students work individually on problems or tasks, and asking students to explain their thinking. The least frequent activities were having students give presentations and lecturing.

These practice frequencies do not always match with the level of importance placed upon each activity. Most notably, lecturing was one of the most unimportant aspects of class activities but is one of the most frequently reported practices during class time. However, having students work with one another and individually on tasks is identified as both important and frequent practices. Furthermore, having students give presentations and holding whole-class discussion were both unimportant and infrequently enacted. For the change initiative, these results are important when considering the needs of the evidence-based instructional practices that have been identified as goals of the change efforts. For example, interactive engagement with frequent formative feedback requires taking breaks in lecture, having students work with one another, and perhaps holding whole-class discussions. These respondents value and enact students working with each other, but lecture frequently and rarely hold whole-class discussions. These new practices may need to be the focus of informal communications (that are supported by the department level expectations) and teaching development opportunities (that are not supported by current expectations or practices). It also may be noted that class presentations are unimportant and infrequently used. This may be of concern to industry stakeholders who require engineers to communicate their findings in presentations. However, this is not a stated goal of the current change initiative. In the next section, the practices and expectations are explored at the individual level to further inform the developing strategy suggestions.

\section{Individual Level}

The individual level of perspective highlights an individual's beliefs about him or herself regarding teaching improvement and teaching practices, and the individual's enactment of these beliefs. Figure 4 shows the responses to three statements regarding individual expectations and five statements that speak to individual practices. These items were both adapted from Deci's and Ryan's exploration into Self-Determination Theory and written by this research team. ${ }^{15}$

The individual expectation statements asked the respondents to choose a response on the continuum from "not true at all" to "very true." The three expectation statements included the efficacy of improvement activities, the respondent's commitment to improving teaching, and respondent's commitment to enacting research-confirmed teaching practices. The truest statement for respondents was the commitment to improving teaching. All statements were at least somewhat true for the respondents. Department $\mathrm{C}$ varied from this trend by having the most respondents who chose the less than somewhat true options. 


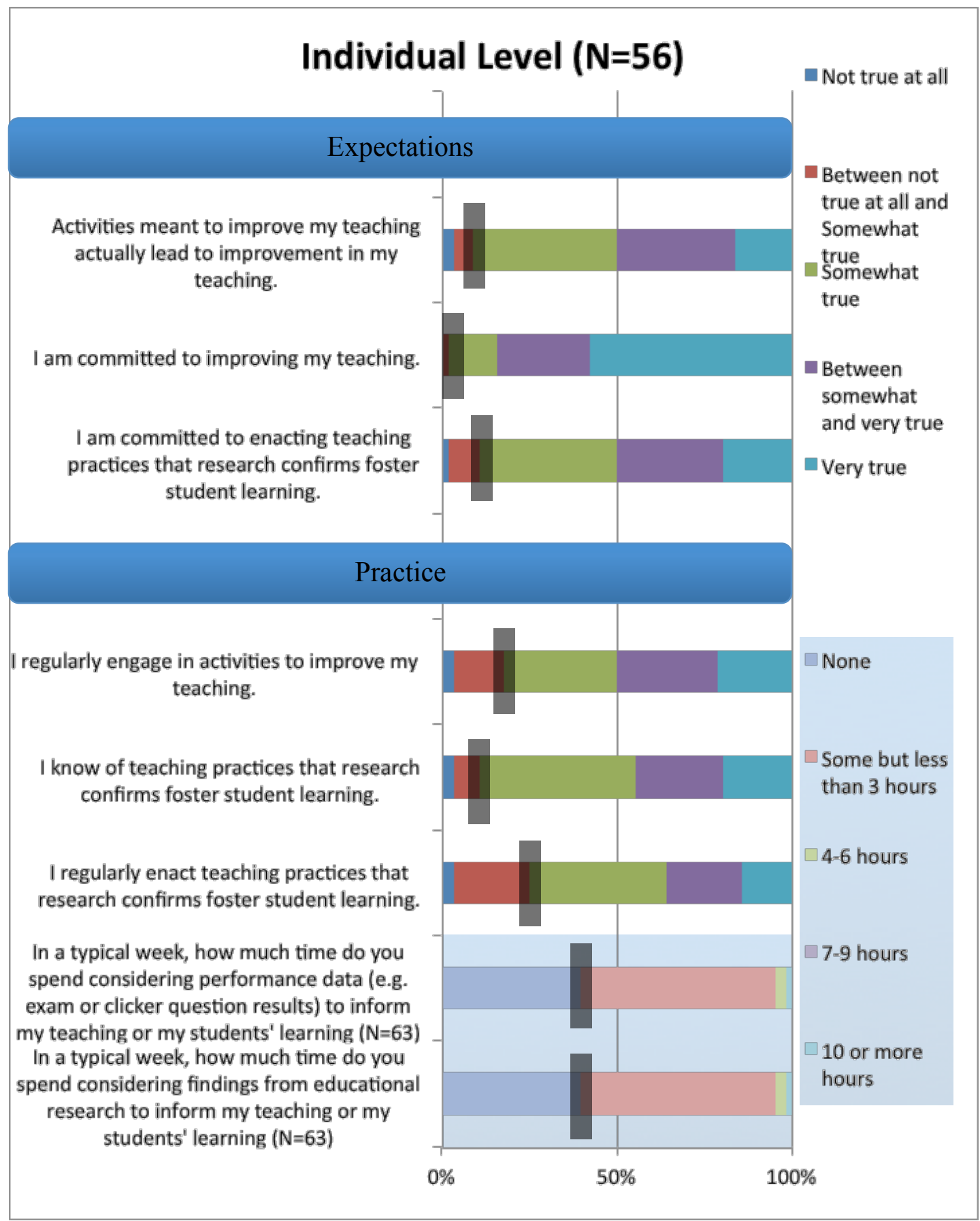

Figure 4. Expectations and practices at the individual level regarding teaching and learning.

The practice statements for the individual level had two different response scales. The first three were also on a continuum from "not true at all" to "very true," while the last two statements" response scales were time spent on activities during a typical week. The first three statements referred to the individual's practice of engaging in activities meant to improve teaching, knowing of research-confirmed teaching practices, and engaging research-confirmed practices. The responses to these statements are often at least somewhat true for respondents. The least true statement for respondents was "I regularly enact teaching practices that research confirms foster 
student learning." As with the expectations for the individual level, Department $\mathrm{C}$ has more responses on the less than "somewhat true" side of the continuum. Department B has more true responses in reply to the regular enactment of research-confirmed teaching practices. For the last two statements regarding the time spent on considering performance data, and considering findings from education research nearly half of the respondents indicated that they did not spend any time on these activities.

At the individual level, the expectations for behavior indicate a positive context for change. The respondents value teaching improvement opportunities and are committed to improving their teaching. However, when it comes to regularly enacting research-confirmed teaching practices only $30 \%$ of the respondents think this statement is more than somewhat true for them. In relation to the goals of the change initiative, it may be that barriers are preventing educators from improving their teaching to the level of enacting research-confirmed teaching practices. These barriers are likely the structure and climate of the environment within which the respondents work. For example, the departments do not hold teaching improvement opportunities, discussions only occur on the order of less than three hours a week, and educators often use lecturing within the classroom. The goal of the change initiative strategy must be to reduce these barriers and to build upon the personal expectations for improving teaching, to motivate educators to engage deeply with change initiative activities.

\section{Relationships between Levels of Perspectives}

In the last portion of each perspective section, we began to explore change initiative strategies that matched the context of the results. In this section, we summarize these findings. First, for most of the results, the responses from the separate engineering departments were consistent. In general, Department A and C responses were slightly less supportive than Department B of the expectations and practices that are needed to promote instructional change. Therefore, the strategies suggested below may need to be more aggressive to be successful within these departments.

At the department level, communication about teaching and learning was valued. However, the departments did not host teaching development opportunities and nearly half of the respondents did not see participation in these opportunities as part of their job. Accordingly, we suggest that the change initiative build upon the informal communication among colleagues to promote evidence-based instructional practices. In addition, respondents do not discuss teaching and learning issues with administrators. The change initiative must build relationships with administrators to inform them of improvement efforts. At the classroom level, having students work together and explain their thinking was practiced. However, in order to enact interactive engagement and frequent formative feedback, the respondents will need to use less lecturing during class time and allow for more discussion among students. This change can be promoted through informal communication and teaching development opportunities. However, because of the expectations at the department level, the change initiative leadership will need to both create these opportunities and motivate department members to attend them. At the individual level, respondents reported a dedication to improve their teaching practice but not enactment of research-confirmed teaching practices. Thus this dedication to improving their teaching is needed as motivation for faculty members to attend teaching development opportunities. In summary, the change initiative leaderships needs to build upon the context of the department by utilizing 
informal communications in supporting change, creating teaching development opportunities, and promoting participation in teaching development opportunities through appeals to an individual's commitment to improving their practice.

\section{Conclusion}

This study is part of a larger case study of the context of an institution-based STEM change initiative. It focused on the expectations and practices at the three levels of perspectives through which a person's life may be viewed. ${ }^{2}$ It was guided by two research questions: (a) Within a doctoral-research institution, what are the characteristics of three engineering academic departments and of individuals within an academic department that influence the improvement of teaching and learning? (b) Using a conceptual framework that attends to the contextual and individual factors, what strategies do these identified features suggest a change agent should privilege when designing change initiative activities for these departments? In response to the first research question, we identified the expectations and practices of department members at the three levels of perspectives. To answer the second research question, we suggest change strategies that fill the needs of the context of the departments and build upon these expectations of individuals to motivate department member participation.

\section{References}

1. Koretsky MD, Bouwma-Gearhart J, Brown S, Dick T, Brubaker-Cole S, Sitomer A, Quardokus Fisher K, ... Ivanovitch J. Enhancing STEM Education at Oregon State University - Year 1. In: American Society for Engineering Education Annual Conference and Exposition. 2015.

2. Hedegaard M. The significance of demands and motives across practices in children's learning and development: An analysis of learning in home and school. Learning, Culture and Social Interaction. 2014; 3(3), 188-194.

3. U.S. Department of Education. Meeting the challenge of a changing world: strengthening education for the $21 \mathrm{st}$ century. U.S. Government Printing Office, Washington, DC. 2006.

4. Association of American Universities (AAU). Undergraduate STEM initiative. Association of American Universities. 2011.

5. National Research Council. Discipline-based educational research: Understanding and improving learning in undergraduate science and engineering. Washington, DC: National Academies Press. 2012.

6. Quardokus KM. Instructional Change in Academic Departments: An Analysis from the Perspective of Two Environment-Focused Change Strategies. Dissertation. Western Michigan University. 2014

7. Bouwma-Gearhart J. Research University STEM Faculty Members' Motivation To Engage In Teaching Professional Development: Building The Choir Through An Appeal To Extrinsic Motivation And Ego. Journal of Science Education and Technology. 2012; 21(5), 558-570.

8. Gibbs G, Knapper C, Picinnin S. Departmental leadership for quality teaching - an international comparative study of effective practice. London, UK: Leadership Foundation for Higher Education. 2009.

10. Johnson DW, Johnson RT. Learning Together and Alone: Cooperative, Competitive, and Individualistic Learning (5th ed.). Boston: Allyn and Bacon. 1999.

11. Wenger E. Communities of Practice: Learning, Meaning and Identity. New York: Cambridge University Press. 1998.

12. Yin RK. Case study research: Design and methods (Vol. 5). Sage. 2009.

13. Knorek JK. Faculty teaching climate: Scale construction and initial validation. Unpublished $\mathrm{PhD}$ dissertation, University of Illinois, Urbana, IL. 2012.

14. http://www.maa.org/programs/faculty-and-departments/curriculum-development-resources/national-studiescollege-calculus/cspcc-project-description

15. Deci EL, Ryan RM. The general causality orientations scale: Self-determination in personality. Journal of Research in Personality. 1985; 19, 109-134. 